\section{Summary}

The family history of diabetes in the first-degree relatives of 1,307 patients at the diagnosis of clinical diabetes is compared with a similar family history in 859 control-group subjects. The results are matched for siblings and parents in different age-groups, and are also compared with the known rate of clinical diabetes at different ages. Under 30 , compared with a nondiabetic control, a diabetic at diagnosis is between 12 and 24 times as likely to have a similarly affected sibling. The corresponding rate for those aged 70 or over, is only one and a half times. The results suggest that only diabetes of early onset has a strong genetic background.

This investigation was supported (in part) by a P.H.S. research grant number CD-00058-01, from the Division of Chronic Diseases,
National Institutes of Health of America, the British Diabetic Association, and the Lawson Tait Memorial Fund.

REFERENCES

Doll, R., and Buch, J. (1950). Ann. Eugen. (Lond.), 15, 135.

Edwards, J. H. (1963). Amer. F. Med., 34, 627.

Harris, H. (1950). Ann. Eugen. (Lond.), 15, 95.

Johnson, G. W. C. (1961). Brit. 7. clin. Pract., 15, 15.

Nilsson, S. E. (1962). Acta med. scand., Suppl. No. 375.

Penrose, L. S. (1953). Acta genet. (Basel), 4, 257.

Pincus, G., and Whire, P. (1933). Amer. $\}$. med. Sci., 186, 1

Report of Working Party appointed by College of General Practitioners (1962). Brit. med. Ұ., 1, 1497. (1962). Brit. med. 7., 1.

Simpson, N. E. (1964). Diabetes, 13, 462.

Steinberg, A. G. (1959). Ann. N.Y. Acad. Sci., 82, 197.

and Wilder, R. M. (1952). Amer. 7. hum. Genet., 4, 113.

Thompson, M. W., and Watson, E. M. (1952). Diabetes, 1, 268.

\title{
Prognosis in Raynaud's Phenomenon After Sympathectomy
}

\author{
E. N. M. JOHNSTON,* M.B., B.CH., M.R.C.P.; R. SUMMERLY, † M.B., CH.B., M.R.C.P., M.R.C.P.ED. ; \\ MARTIN BIRNSTINGL, $\ddagger$ M.S., F.R.C.S.
}

Brit. med. F., 1965, 1, 962-964

Raynaud (1862, 1874) first described "local syncope of the extremities," and Lewis and Pickering (1934) recognized that this phenomenon could result from hypersensitivity of the digital arteries to cold (primary Raynaud's phenomenon) or could be secondary to connective-tissue disorders, arteriosclerosis, local injury, long-standing vibration, or compression of the subclavian artery at the thoracic outlet. Some patients apparently suffering from primary Raynaud's phenomenon ultimately develop systemic scleroderma, the Raynaud's phenomenon preceding other features of this disease by several years.

Sympathectomy has been used in the treatment of severe Raynaud's phenomenon of the hands since 1928, and although the immediate post-operative results may be most encouraging the late results often are not. Few of the follow-up reports, however, make any genuine reappraisal of the late operative results in those patients initially thought to be suffering from primary Raynaud's phenomenon who subsequently developed a connective-tissue disorder. de Takats and Fowler (1962) consider that the chief reason for failure of upper thoracic sympathectomy stems from operating on patients who are suffering from incipient or unrecognized connective-tissue disease, that the presence of such disease is a contraindication to sympathectomy, and that the operation may precipitate dissemination, especially in lupus erythematosus.

We report the results of a follow-up study of 75 patients with severe Raynaud's phenomenon of the hands who had been treated by sympathectomy 3 to 24 years earlier. We have been especially interested in the subsequent fate of those patients who were thought to be suffering from primary Raynaud's phenomenon, and we have tried to relate the surgical result in those patients to the final diagnosis.

\section{Materials and Methods}

Seventy-five patients who had had upper thoracic sympathectomy for severe Raynaud's phenomenon in the surgical

\footnotetext{
* Consultant Dermatologist, Nottingham and Mansfield Hospital Group. + St. Thomas's Hospital, London.
}

¥Consultant Surgeon, St. Bartholomew's Hospital, London. professorial units of St. Bartholomew's and St. Thomas's Hospitals between 1939 and 1960 and who agreed to attend special follow-up clinics for further investigation formed the group studied. Reappraisal of the symptoms, signs, earlier investigations, and operative results was made.

Supine barium swallows or oesophageal manometry (by the method of Dornhorst et al., 1954) were done at follow-up on the patients with primary Raynaud's phenomenon and whenever systemic scleroderma was suspected. Blood investigations consisted of haematology (haemoglobin, white-cell count, differential count, film, and blood-sedimentation rate), serology (Wassermann reaction, Rose-Waaler and latex fixation tests, L.E. cells, antinuclear factor, and cold agglutinins), and biochemistry (blood urea, serum proteins, electrophoresis, cryoglobulins). Routine urinalysis (with microscopy) was carried out. Radiographs of the chest, hands, and thoracic inlet were taken. Macular telangiectases similar to those which may occur on the hands, lips, buccal mucosa, and face in systemic scleroderma were searched for in an unselected group of 200 dermatological out-patients (120 females, 80 males) aged 15 to 70 years who had never suffered from Raynaud's phenomenon.

\section{Definitions}

Primary Raynaud's Phenomenon.-We have adhered to the criteria suggested by Allen and Brown (1932), namely: (1) the Raynaud's phenomenon should be bilateral and paroxysmal; (2) there should be no clinical evidence of diseases of the peripheral arteries or other conditions known to give rise to secondary Raynaud's phenomenon; (3) necrotic lesions, if present, should be superficial and confined to the skin of the finger-tips; and (4) symptoms should have been present for at least two years at the time of diagnosis.

Systemic Scleroderma.-This is the form of scleroderma in which systemic visceral manifestations may occur; it embraces the term "progressive systemic sclerosis" but excludes disseminated morphoea.

Primary Raynaud's Phenomenon with Scleroderma-like Changes.-We have used this term for patients whose condition 
fell midway between severe primary Raynaud's phenomenon and systemic scleroderma and who may have incipient systemic scleroderma. They had severe trophic changes confined to the fingers, a small number of macular telangiectases on the hands or lips, but no other skin changes or evidence of systemic involvement.

\section{Results}

There were 51 females and 24 males; follow-up was from 3 to 24 years (Table I). Sixty-one patients had had bilateral sympathectomies and 14 unilateral.

The pre-operative diagnoses are shown in Table II. The miscellaneous group comprised two patients suffering from systemic lupus erythematosus and one patient who had dermatomyositis. All three had scarring atrophic lesions on the fingers and distressingly severe Raynaud's phenomenon.

TABLB I.-Duration of Follow-up After Sympathectomy

\begin{tabular}{lll|l|l|l|l|l}
\hline Years &.. &.. & $3-5$ & $6-10$ & $11-15$ & $16-20$ & $21-24$ \\
No. of patients &. &. & 30 & 38 & 5 & 1 & 1 \\
\hline
\end{tabular}

TABLE II.-Results of Sympathectomy

\begin{tabular}{|c|c|c|c|}
\hline \multicolumn{2}{|l|}{ Pre-operative Diagnosis } & Total & No. Improved \\
\hline $\begin{array}{l}\text { Primary Raynaud's phenomenon.. } \\
\text { Digital-artery thrombosis } \\
\text { Di. }\end{array}$ & $\begin{array}{ll}\because & . \\
\because & \cdots \\
\therefore & \cdots\end{array}$ & $\begin{array}{r}43 \\
21 \\
8 \\
3\end{array}$ & $\begin{array}{l}25(58 \%) \\
15(71 \%) \\
2 \\
0\end{array}$ \\
\hline
\end{tabular}

None of the patients was cured by operation. Improvement was recorded if, as a result of the operation, the attacks of Raynaud's phenomenon became less frequent and less severe, if healing of finger-tip necroses occurred, and if episodes of finger-tip necrosis and paronychial infection were reduced. Patients who experienced temporary relief lasting only one year were classed as operative failures.

The results of sympathectomy in relation to the pre-operative diagnoses are shown in Table II. The percentage suocess in primary Raynaud's phenomenon was $58 \%$, and in digital artery thrombosis $71 \%$. None of the three patients in the miscellaneous group was helped, nor did the operation precipitate any deterioration in their condition.

TABlB III.-Effect of Revision of Diagnosis on Outcome in Primary Raynaud's Phenomenon

\begin{tabular}{|c|c|c|}
\hline Final Diagnosis & Total & No. Improved \\
\hline $\begin{array}{l}\text { Primary Raynaud's phenomenon confirmed } \ldots \\
\text { Systemic scleroderma } \\
\text { Primary Ruynaud's phenomenon with } \\
\text { derma-like changes } \\
\begin{array}{l}\text { delero- } \\
\text {.. }\end{array} \text {.. }\end{array}$ & $\begin{array}{r}31 \\
8 \\
4\end{array}$ & $\begin{array}{l}18(58 \%) \\
5\end{array}$ \\
\hline
\end{tabular}

Of the 43 patients diagnosed initially as having primary Raynaud's phenomenon, at follow-up 31 still appeared to be in this category, eight had developed systemic scleroderma, and four were placed in the intermediate group of primary Raynaud's phenomenon with scleroderma-like changes.

The effect of the revised diagnosis on the late operative results in primary Raynaud's phenomenon is shown in Table III. The striking feature is that the overall success rate $(58 \%)$ in the patients with confirmed primary Raynaud's phenomenon shows no improvement, because five of the patients who had developed systemic scleroderma and two in the intermediate group had also benefited by sympathectomy.

One other patient initially diagnosed as having Raynaud's phenomenon secondary to digital-artery thrombosis had developed systemic scleroderma at follow-up. Her case history demonstrates a feature of special interest.

A woman aged 50 developed severe Raynaud's phenomenon, mainly of the right hand complicated by gangrene of the finger-tips. A right-sided upper thoracic sympathectomy was performed. Ten years later both hands were sclerotic, and there were telangiectases on the face, lips, and fingers. Oesophageal studies confirmed the presence of systemic scleroderma. Despite the symptomatic improvement produced by the operation in the right hand, the rate of progress of the disease had been the same in both upper limbs.

Control Group: Incidence of Macular Telangiectases.-One to five macular telangiectases were found on the face in each of 40 patients $(20 \%)$ in the older age-groups ; none were found on the hands, lips, or buccal mucosa.

\section{Discussion}

The late results of upper thoracic sympathectomy in primary Raynaud's phenomenon corresponded with previous reports (Buchanan et al., 1952; Gifford et al., 1958; Hall and Hillestad, 1960). All our patients were improved during the first six months after the operation, although some degree of cold hypersensitivity persisted in spite of adequate sympathetic denervation; return of symptoms occurred between the first and second year after surgery. However, 18 (58\%) patients stated at follow-up that their symptoms were still less severe than before the operation (Table III). As in earlier reports, the best results occurred in patients with digital-artery thrombosis; immediately after the operation tissue loss was minimized and gangrene averted, while at follow-up $71 \%$ still had an improvement in the Raynaud's phenomenon.

The most interesting results occurred in the 17 patients with systemic scleroderma. Of the eight patients who at the time of operation had sclerodactyly and widespread sclerosis of the upper limbs, only two were helped. In the eight patients with the slowly progressive variant of the disease characterized by many years of severe Raynaud's phenomenon the operative results were similar to those in the patients with confirmed primary Raynaud's phenomenon. The sympathectomy did not seem to influence the tempo of the disease in these patients, as illustrated in our patient whose initial symptoms were predominantly unilateral (see above).

The difficulty of recognizing systemic scleroderma is demonstrated by our follow-up. Of the 43 patients initially diagnosed as having primary Raynaud's phenomenon, eight (19\%) had developed systemic scleroderma 6 to 24 years later. The diagnostic difficulties arise, firstly, because in systemic scleroderma Raynaud's phenomenon may occur with visceral involvement but without skin sclerosis (Tuffanelli and Winkelmann, 1961), and, secondly, because the slowly progressive variant of systemic scleroderma begins with Raynaud's phenomenon and trophic changes on the fingers but may not involve the arms, face, or viscera for several years (in this series the time interval was 3 to 20 years). Specialized procedures such as the measurement of the sensory chronaxie of the skin (Jablonska et al., 1958, 1959, 1962) and histological studies of the cutaneous nerve networks (Pawlowski, 1963) are said to be helpful in distinguishing severe primary Raynaud's phenomenon from incipient systemic scleroderma, but are not readily available.

It is often stated that Raynaud's phenomenon of early onset associated with "hereditary cold fingers," chilblains, and a positive family history is tantamount to a diagnosis of primary Raynaud's phenomenon. This is not correct ; three of our patients with apparent primary Raynaud's phenomenon who developed systemic scleroderma gave such histories. This suggests that hypersensitivity to cold may predispose to systemic scleroderma, or at any rate may coexist. Another diagnostic difficulty arises, albeit uncommonly, when the Raynaud's phenomenon of systemic scleroderma is initially onosided, suggesting digital-artery occlusion.

Finger-tip necroses, accepted in primary Raynaud's phenomenon by Allen and Brown (1932), and Allen et al. (1962), occurred in only one of our patients with confirmed primary Raynaud's phenomenon. We believe that loss of tissue 
from the finger-tips, especially if associated with resorption of the terminal phalanges, points towards some other disease process, in particular systemic scleroderma.

Flat (macular) polygonal telangiectases on the hands are unusual in patients with Raynaud's phenomenon. In this series they occurred in the patients with systemic scleroderma, and in very small numbers (one to three) in five patients with confirmed primary Raynaud's phenomenon. We believe that in patients with Raynaud's phenomenon, macular telangiectases may be the most valuable early clinical sign of incipient or overt systemic scleroderma if present on the hands, but are of less significance if found on the face alone.

Brachial arteriography is not helpful in distinguishing severe primary Raynaud's phenomenon from early systemic scleroderma. This procedure was performed pre-operatively on four of the patients initially diagnosed as having primary Raynaud's phenomenon who later developed systemic scleroderma. In two the arteriograms were normal, and in two digital-arterial blocks were demonstrated, but there was no specific radiological change to indicate that systemic scleroderma would ensue. Apart from this, arteriography affords a reliable method of diagnosing digital-arterial blockage and was used in the pre-operative assessment of a total of 15 of our patients.

In the 727 patients suffering from systemic scleroderma reviewed by Tuffanelli and Winkelmann (1961) the oesophagus was by far the most commonly involved viscus ( $67 \%$ of patients), and for this reason oesophageal manometry or anti-gravity (supine) barium swallows were performed at follow-up in the patients with primary Raynaud's phenomenon. No unsuspected examples of systemic scleroderma were discovered, and in the borderline group (primary Raynaud's phenomenon with scleroderma-like changes) these investigations did not help to clarify the diagnosis. In those patients with apparent primary Raynaud's phenomenon who developed systemic scleroderma the oesophageal abnormalities merely confirmed our clinical suspicions. Similarly, serological tests (L.E. cells, sheep-cell agglutination, latex fixation, and antinuclear factor) did not help to separate incipient systemic scleroderma from apparent primary Raynaud's phenomenon in this series. These investigations were abnormal in two patients who progressed to systemic scleroderma, but not before the diagnosis was clinically obvious.

A good response to sympathectomy in doubtful cases cannot be taken as confirmatory evidence of primary Raynaud's phenomenon, since improvement after surgery occurred in five of our patients with the slowly evolving variety of systemic scleroderma.

\section{Summary}

Seventy-five patients who had had upper thoracic sympathectomy for Raynaud's phenomenon of the hands 3 to 24 years earlier were reviewed. The pre-operative diagnoses were primary Raynaud's phenomenon in 43, digital-artery thrombosis in 21 , systemic scleroderma in 8 , systemic lupus erythematosus in 2, and dermatomyositis in 1 .

Eight patients apparently suffering from primary Raynaud's phenomenon at the time of operation had developed systemic scleroderma at follow-up, the Raynaud's phenomenon preceding other features of the disease by an interval of from 3 to 20 years.

The late results of sympathectomy were best in digital-artery thrombosis ( $71 \%$ success) and in confirmed primary Raynaud's phenomenon ( $58 \%$ success). The results were poor in patients who had advanced systemic scleroderma at the time of operation and in the three patients who had other connective-tissue disorders, but no dissemination of the condition resulted from operation.

The patients with apparent primary Raynaud's phenomenon who ultimately developed systemic scleroderma responded to sympathectomy; the operative result gave no indication of the true diagnosis. In such patients finger-tip necroses and macular telangiectases on the hands should suggest incipient systemic scleroderma.

We are grateful to Dr. H. J. Wallace for suggesting this study. We thank the physicians and surgeons of St. Thomas's Hospital, and Professor G. W. Taylor, St. Bartholomew's Hospital, for permission to study patients under their care. This work was supported by a grant to one of us (E. N. M. J.) from the St. Thomas's Hospital Endowment Fund.

\section{REFERENCES}

Allen, E. V., Barker, N. W., and Hines, E. A., jun. (1962). Peripheral Vascular Diseases, 3rd ed., p. 137. Saunders, Philadelphia.

- and Brown, G. E. (1932). Amer. f. med. Sci., 183, 187.

Buchanan, J. L., Cranley, J. J., and Linton, R. R. (1952). Surgery, 31, 62.

de Takats, G., and Fowler, E. F. (1962). f. Amer. med. Ass., 179, 1.

Dornhorst, A. C., Harrison, K., and Pierce, J. W. (1954). Lancet, 1, 695. Gifford, R. W., Hines, E. A., jun., and Craig, W. McK. (1958). Circulation, 17, 5 .

Hall, K. V., and Hillestad, L. K. (1960). Angiology, 11, 186

Jablonska, S., Bubnow, B., and Lukasiak, B. (1958). Brit. f. Derm., 70

37.

二- $=$ and Szczepánski, A. (1962). Ibid., 74, 174.

Lewis, T., and Pickering, G. W. (1934). Clin. Sci., 1, 327

Pawlowski, A. (1963). Arch. Derm., 88, 868.

Raynaud, A. G. M (1862). Thèse de Doct. Paris, Rignaux.

- (1874). Arch. gén. Méd., 5, 189.

Tuffanelli, D. L., and Winkelmann, R. K. (1961). Arch. Derm., 84,
Ashby et al. (1964) discussed some of the literature on eosinophilic granuloma of the gastro-intestinal tract in man. They referred to 47 papers which describe a total of 89 cases and stated that, although " the herring parasite" may not be responsible for all these cases, it may well be the causative agent in European territories. * Assistant Director, Commonwealth Bureau of Helminthology, St.

\section{Literature}

From the literature and original observations on "Eustoma rotundatum," a species provisionally referred to as Pseudanisakis rotundata in this paper, attention should be drawn to the following, which show not only that the account by Ashby et al. is greatly oversimplified but also that there is a dire need for more detailed work on all aspects of the biology of those roundworms, which are said to establish themselves temporarily or 